mentioned as a cause of macrocytosis (p. 142). These are minor points. The format is pleasant and there are few spelling mistakes although hoary errors involving melaena, pruritus, haematology (see contents page) and ophthalmoscopy appear.

The second assessment was to test the book as if $I$ had been the house physician on recent 'takes'. It succeeded with cardiovascular and respiratory conditions. I thought syncope from G.I. haemorrhage had it beaten until I found the information under 'collapse'. On the other hand the later systems were a bit thin; the approach to undiagnosed vomiting and diarrhoea-including faecal impaction-and urinary infections were not covered. Set headings such as Crohn's disease or ulcerative colitis presuppose a diagnosis has already been made. Problem solving is perhaps of more importance hence the value of headings such as jaundice, dementia, haematuria and acute monoarthritis with the important message not to miss septic arthritis.

Finally, how does the book compare with existing pocket guides? These tend to be directed at medical residents, e.g., The Medical Residents Manual, and my own Guide to House Physicians, or they limit the contents to acute medical emergencies.

In my view, the greatest value of Handbook of Hospital Medicine will be to the house physician. By present day standards it is reasonably priced.

J. G. LEWIS
Edgware General Hospital,
Edgware,
Middlesex.

\section{Hypertension: Physiopathology and Treatment}

By Jacques Genest, Otto Kuchel, Pavel Hamet and Marc CANTIN. 2nd edn. Pp. xix +1318 , illustrated. McGraw Hill Book Company, New York, San Francisco, Auckland, London, Paris, Sydney, 1983. $£ 73.95$.

The first edition of Hypertension: Physiopathology and Treatment in 1977 marked the 25th anniversary of the Montreal Hypertension Research Group. I found it a difficult book to use in large part, surprisingly enough, due to the typography and lay-out. All this has been handsomely remedied and the second edition is an excellent book to handle, look at, find your way about-and to read.

The text splits about 50-50 into sections dealing with the pathophysiology of experimental and human hypertension and with clinical hypertension. The major changes in subject matter since 1977 are advances in the understanding of renin physiology and of ion transport and of cell membrane physiology in hypertension, improved analytical techniques of renin and catecholamine measurement and converting enzyme inhibitor drugs.

The sections on pathophysiology are synthesized in invaluable chapters expressing the personal views of the mechanisms of hypertension by Genest, Laragh, the Glasgow group, Folkow, Doyle and Dustan.

As in the previous edition, there is an international contribution from experts in five continents. It is not being chauvinistic in view of the geographical availability of drugs to see that the chapter on drug treatment is written from the U.K. (by Prichard and Owens).

For a speciality with so much research and clinical activity, the book is remarkably up-to-date and has a quality of sparkling freshness. The 'sell by date' is a few years hence. This must be today's foremost reference book in hypertension and everyone with a serious interest in the subject will want a copy.

B. I. HOFFBRAND Archway Wing, Whittington Hospital, London NI9.
Rheumatology and Rehabilitation: Diagnosis and Management

Edited by HEDley BERRY, ERIC HAMILTON and JOH Goodwill. Pp. 266, illustrated. Croom Helm, London, Canberræ 1983. $£ 16.95$ (hardback), $£ 8.95$ (paperback).

This will prove a useful book for undergraduates although will certainly not replace the standard reference books for those trum interested in the subjects of both rheumatology and rehabilitatiof?

The section on rehabilitation, often a much neglected area in shw text books, will be extremely useful as an introduction to the specialty although the omission of a chapter on spinal injuries tetraplegia surprised me somewhat. I was glad to see chapters of physiotherapy, speech therapy and occupational therapy emphasis ing the importance of each of these disciplines and the overab assessment of disabled patients is comprehensively covered.

This is a multi-author book which perhaps explains some of the duplication which occurs between chapters, especially as far as the drug therapy of the rheumatological diseases is concerned. There were also one or two rather inexplicable inconsistencies. Moef chapters however were clearly and concisely written, and I found tes chapter on radiology particularly helpful. I am sure that medie? students and paramedical staff will find this volume easy to reaf. They will certainly not regret acquiring a copy.

M. Webley Stoke Mandeville Hospital, $\underset{ }{ }$ Aylesbury, ? Bucks HP21 8AL. $\omega$

\section{X-Ray Interpretation for the MRCP}

By P. S. PARfrey and B. C. Cramer. Pp. 238, illustrated Churchill Livingstone, Edinburgh, London, Melbourne, New York, 1983. £7.95.

There has long been a desperate need for a book like this which covers simply and quickly radiological material which M.R candidates are expected to be able to interpret. It is a well-prodiced and extremely readable book with illustrations of excellent quâे lif and I would strongly recommend it to all M.R.C.P. candidates indeed most General Physicians and senior medical students wouta gain much from reading it.

I found it an enjoyable book to read, and its dynamic question añ answer style made it read like an interesting novel.

Of the 20 slides shown in the spot diagnosis part of the written M.R.C.P. examination, generally at least five are radiographs are candidates, therefore, have to cover this field in considerable deta Also, more recently, some specialized procedures such as chess. tomographs, ultrasounds and myelograms have also been showi. and a number of these investigations are covered and examples are shown in this useful book. There is also a short introductory chaptef on how to read X-rays. This is then followed by the X-rays themselves, accompanied by 100 questions and their answe including a short discussion.

My only criticism of this book is that I thought the I.V.Ps shovip were of slightly poor technical quality compared with the other rays. This made these investigations difficult to interpret and I doubt whether most General Physicians would have got these answe? correct. Otherwise, the illustrations were of excellent quality. I thin this moderately-priced paperback will soon establish itself as standard text book for candidates preparing for the M.R.C.E. examination and it is to be hoped that the publishers will continue no produce text books of a similar standard in other specialiti\& required for the examination. 